\title{
Comparative investigation of indigo blue dye removal efficiency of activated carbon and natural clay in adsorption/ultrafiltration system
}

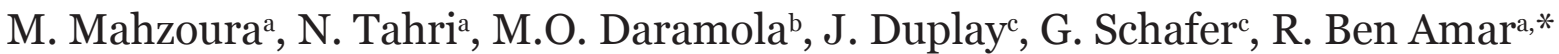 \\ ${ }^{a}$ Laboratory of Materials Sciences and Environment, Faculty of Sciences of Sfax, University of Sfax, Road Soukra Km 4, 300o Sfax, \\ Tunisia, email: missaoui.mahzoura@yahoo.fr (M. Mahzoura), tahri.nouha@yahoo.fr, (N. Tahri), Tel. +216216o3013, \\ email: benamar.raja@yahoo.com (R.B.Amar) \\ ${ }^{b}$ School of Chemical and Metallurgical Engineering, Faculty of Engineering and the Built Environment, University of the \\ Witwatersrand, Wits 2050, Johannesburg, South Africa \\ ${ }^{c}$ EOST, Laboratory of hydrology and geochemistry of Strasbourg, 1 street Blessig 670840 Strasbourg cedex, France, \\ email: jduplay@unistra.fr (J.Duplay),schafer@unistra.fr (G.Schafer)
}

Received 21 September 2018; Accepted 4 May 2019

\section{a bstract}

In the present study, indigo blue dye removal efficiency of activated carbon (AC) and natural clay (NC) was evaluated and compared, firstly in an adsorption unit, and then in an adsorption coupling ultrafiltration (A/UF) system. Effect of operating variables like $\mathrm{pH}$, contact time, adsorbent dosage, initial dyes concentration during the adsorption was investigated and consequently optimised. The optimal conditions were employed for the adsorbents during the removal of the dye in the A/UF system. The optimal amount of $\mathrm{NC}$ and $\mathrm{AC}$ was $0.4 \mathrm{~g} / \mathrm{L}$ and $0.3 \mathrm{~g} / \mathrm{L}$, respectively, and $\mathrm{NC}$ and $\mathrm{AC}$ displayed adsorption capacity of $57 \mathrm{mg} / \mathrm{g}$ and $53 \mathrm{mg} / \mathrm{g}$, respectively, at this condition. Application of UF reveals a decrease of membrane fouling for both adsorbents in A/UF system. In addition, colour retention, when the adsorbents were used in A/UF, increased significantly from $90.5 \%$ to $99 \%$ as compared to using adsorption only. The efficiency of the membrane regeneration was estimated by the determination of the water permeability after rinsing. It is noteworthy to mention that a total regeneration of the membrane after the application of continous hybrid A/UF was achieved, however, the use of UF alone exhibited a fouling decrease by $40 \%$.

Keywords: Indigo blue dye aqueous solution; Adsorption; Ultrafiltration; Continous hybrid treatment; Adsorbent dose; Decolorization

\section{Introduction}

The use of different types of synthetic dyes in various industries, for instance textile industry, generates high volume of coloured wastewater. Some of these dyes are toxic and should be removed or degraded prior to disposal into sea. For this reason, disposal of dye-contaminating wastewater constitutes a serious environmental concern becauce ineffective disposal of these pollutants poses health risks [1]. Thus, treatment of dye-contami- nated wastewater is an important issue in environmental remediation $[2,3]$.

Nowadays, several treatment methods are available for degradation and removal of dyes from wastewater. A few of these methods include, chemical oxidation [4-8], filtration $[9,10]$, biological treatment $[11,12]$, biochemical degradations [6], ion-exchange removal [8], adsorption [13-17], photocatalysis $[18,19]$. In comparison with chemical and biological methods, membrane based method such as nanofiltration (NF) and utrafiltration (UF), have emerged a promising physical treatment method. Advantages of membrane based method, in comparison with other meth-

*Corresponding author. 
ods, include easiness and green operation, high efficiency and low cost treatment [20]. UF membrane process is a relatively low pressure (0.04-1 MPa), and consumes less energy when compared to the NF process [21]. However, effective removal of small size compounds and dissolved contaminants such as dyes cannot be accomplished with a single stage UF process because of the relatively large pore size of the UF membrane.

UF system combined with other conventional separation technologies such as adsorption and coagulation/ flocculation, has been proven to be an efficient approach to increasing effective removal of the compounds via membrane separation [22,23]. It should be mentioned that adsorption has been recognized as the most popular treatment process for removing dyes from aqueous solution because of its high removal efficiency, simple operability and economic feasibility (low-cost, easy recovery and reuse of adsorbent) [24]. Adsorption using activated carbon appears to be the best for the removal of dye from aqueous solution $[25,26]$. Despite the removal effectiveness of the $\mathrm{AC}$, high cost of the $\mathrm{AC}$ and difficulty in regenerating $\mathrm{AC}$ after use are mitigating factors. Therefore there is a need to search for relatively cheap adsorbents to remove pollutants from wastewater.

Many studies in recent years have focused on the use of low cost adsorbents prepared from waste materials such as activated carbon from agricultural wastes [27]. Amongst the low cost adsorbents, the use of materials such as clay, sepiolite, zeolite, diatomite, resin and bentonite $[28,29]$ provides several advantages over the others because they one readily available due to their availability, non toxic and have high sorption capacity [30-32]. For instance, clay is abundant, inexpensive and environmentally friendly and it has a high adsorption capacity attributable its to due to their lamellar structure that offers high specific surface area and the possibility of adsorbing ions and organic polar molecules in intercalary positions [33-35]. Natural clay is able to remove up to $98 \%$ of colour from effluents containing anionic dyes from the dyeing process $[27,36]$. Furthermore, the use of hybrid adsorption/ultrafiltration (A/UF) system is increasingly being investigated for organic contaminants removal from wastewater and for minimization of fouling caused by synthetic and natural organic matter [23-29]. Therefore, the use of A/UF system in treatment dye contaminated creates could be a promising option for effect due removal of dye by exploring the synergy between adsorption and membrane system to remove dye from wastewater.

Against this background, in this present study, separation performance of a single adsorption unit and continous adsorption/ultrafiltration (A/UF) hybrid system was compared during the removal of indigo blue dye. For the adsorption, natural clay (NC) and commercial activated carbon (AC) were used. In addition, effect of operating variables, such as contact time, initial dye concentration, initial solution $\mathrm{pH}$ and temperature, on the adsorption capacity of $\mathrm{NC}$ and AC during the dye removal was investigated. Furthermore, adsorption kinetics and isotherm studies were undertaken to determine the adsorbate removal rate and the maximum adsorption capacity. Thermodynamic properties, such as enthalpy, entropy and the free energy were also estimated to provide insight into the adsorption mechanism during the adsorption removal of the dye.

\section{Materials and methods}

\subsection{Preparation of synthetic dye solution}

Experiments were conducted using indigo blue dye $\left(\mathrm{C}_{16} \mathrm{H}_{10} \mathrm{~N}_{2} \mathrm{O}_{2}\right)$ provided by SITEX company located in Monastir-Tunisia. Indigo blue is insoluble in water and poorly soluble in most of common solvents, so it has to be made soluble by reduction under alkaline condition. Sodium hydrosulfite, which is universally used as a reducing agent, was used in the reduction reaction. The composition of the synthetic model solution is given in Table 1.

\subsection{Adsorbents}

To study the adsorption capacity to remove indigo blue dye, two adsorbents represented by natural clay (NC) of Tunisia origin and commercial activated carbon (AC) were used. NC was collected from Fouchana region located in the north-east of Tunisia, and AC was purchased from NORIT, USA. The quantitative chemical composition and the specific surface area of $\mathrm{NC}$ and $\mathrm{AC}$ were obtained using X-ray fluorescence (XRF) and $\mathrm{N}_{2}$ physisorption experiments at 77 K (with a Micrometrics Asap 2010).

$\mathrm{X}$-Ray diffraction (XRD) analysis was used to investigate the crystalline structure. The X-ray diffraction pattern

Table 1

Composition of the synthetic colored solution

\begin{tabular}{ll}
\hline Component & $\mathrm{C}(\mathrm{g} / \mathrm{l})$ \\
\hline Sulfur blue & 5 \\
Indigo Blue & 1 \\
Wetting & 0.5 \\
$\mathrm{NaOH}$ & $\mathrm{pH}=11$ \\
Sodium hydrosulfite & 0.5 \\
Softeners & 0.3 \\
Sequestering & 0.1 \\
\hline
\end{tabular}

Table 2

Elemental composition for $\mathrm{NC}$ and $\mathrm{AC}$

\begin{tabular}{lll}
\hline Component & $\mathrm{NC}$ & $\mathrm{AC}$ \\
\hline Smectite & $60.00 \%$ & - \\
Kaolinite & $30.00 \%$ & - \\
Illite & $10.00 \%$ & - \\
$\mathrm{Si}_{2} \mathrm{O}$ & $52.10 \%$ & $0.09 \%$ \\
$\mathrm{Al}_{2} \mathrm{O}_{3}$ & $22.70 \%$ & $0.69 \%$ \\
$\mathrm{CaO}$ & $1.01 \%$ & $0.60 \%$ \\
$\mathrm{Fe}_{2} \mathrm{O}_{3}$ & $9.15 \%$ & $0.06 \%$ \\
$\mathrm{Na}_{2} \mathrm{O}$ & $0.02 \%$ & - \\
$\mathrm{K}_{2} \mathrm{O}$ & $2.46 \%$ & - \\
$\mathrm{MgO}$ & $2.17 \%$ & - \\
$\mathrm{MnO}$ & $0.014 \%$ & $0.05 \%$ \\
$\mathrm{P}_{2} \mathrm{O}_{5}$ & $0.15 \%$ & - \\
$\mathrm{S}$ & & $0.04 \%$ \\
$\mathrm{C}$ & - & $87.11 \%$ \\
\hline
\end{tabular}


of powder was recorded on a Phillips-1730 (PAN analytical) X-ray diffractometer using $\mathrm{Cu} \mathrm{K} \alpha$ radiation $(\lambda=1.54 \AA$ ). Morphology and surface characteristics of the adsorbents before and after adsorption were checked via scanning electron microscopy (SEM) using a Philips XL20 Scanning Electron Microscope at an accelerating voltage of $10 \mathrm{kV}$. FTIR spectra of natural adsorbents were obtained in the region 2560-500 $\mathrm{cm}^{-1}$ using FTIR spectrometer, type Perkin Elmer Spectrum100-FT-Spectrometer model, at room temperature without $\mathrm{KBr}$. The characteristics of $\mathrm{AC}$ provided by the manufacturer are given in Table 3.

\subsection{Experimental}

\subsubsection{Batch adsorption experiment}

Adsorption experiments were carried out in batch mode. Solution containing known concentration of adsorbate and accurately weighed amount of adsorbent were introduced in glass flask, sealed and agitated with a magnetic stirrer at $450 \mathrm{rpm}$. The $\mathrm{pH}$ was adjusted by adding $\mathrm{HCl}$ (o.1 M) and $\mathrm{NaOH}(0.1 \mathrm{M})$ and the ambient temperature with a water bath controller. Experiments were carried out over $6 \mathrm{~h}$ to ensure that adsorptive equilibrium was attained. A sample of $10 \mathrm{~mL}$ was collected at 20 min intervals and filtered to separate the adsorbent from the solution.

\subsubsection{Adsorption-UF hybrid experiments}

The lab-scale experimental setup of the A/UF hybrid system is illustrated in Fig. 1. The experiments were performed with multitubular alumina/zirconia membrane of molecular weight cutt-off (MWCO) of $150 \mathrm{kDa}$ and a surface area of $0.155 \mathrm{~m}^{2}$ provided by PAL company. The UF membrane has a water permeability of $230 \mathrm{~L} / \mathrm{h} \mathrm{m}^{2} \mathrm{bar}$. The synthetic dye solution mixed with adsorbent particles was put in the feed tank. The initial solution $\mathrm{pH}$ was adjusted using acidic $(\mathrm{HCl} 0.1 \mathrm{M})$ or basic $(\mathrm{NaOH} 0.1 \mathrm{M})$ solutions and the temperature was maintained constant using a heat exchanger. A mild stirring was provided at $450 \mathrm{rpm}$ for 15-20 min, then the solution was pumped from the feed tank to the membrane module. The retentate was recycled back to the feed tank and the initial volume was maintained constant with adding an adequate volume of feed solution $\left(V_{f}\right)$ in the feed tank equal to the volume of the permeate extracted $\left(V_{p}\right)$.

The performance of the UF process enhanced with adsorption was evaluated using permeate flux and the pollutants. The efficiency of the color removal after each treatment was determined using the rejection percentage (R) defined as:
$R=\left.\left\lfloor\left(1-\frac{C_{p}}{C_{f}}\right)\right\rfloor\right|_{\times 100}$

where $C_{p}$ and $C_{f}$ are the concentration of the dye in the permeate and in the feed solution, respectively.

\subsection{Analytical methods}

\subsubsection{Dye concentration and removalcapacity}

Dye concentration was determined colorimetrically by measuring at maximum absorbance at $620 \mathrm{~nm}$ using UVvisible spectrophotometer. The absorbance-concentra- tion profile was obtained by calibration curve of absorbance versus concentration of the dye solution.

The amount of dye adsorbed per unit weight at equilibrium $\left(q_{e}\right)$ was calculated using Eq. (2):

$$
q_{e}=\left(\frac{C_{i}-C_{e}}{m}\right) \times V
$$

where $C_{i}$ is the initial dye concentration $(\mathrm{mg} / \mathrm{L}) ; C_{e} \quad$ is the dye concentration at adsorption equilibrium $(\mathrm{mg} / \mathrm{L}) ; V$ is the volume of the dye solution (L); and $m$ is the weight of the adsorbent $(\mathrm{g})$.

\subsubsection{Adsorption isotherm}

The adsorption isotherm corresponds to the distribution of molecules between the liquid phase and the solid phase when the adsorption process reaches an equilibrium state. To understand the adsorption mechanism via the adsorp-

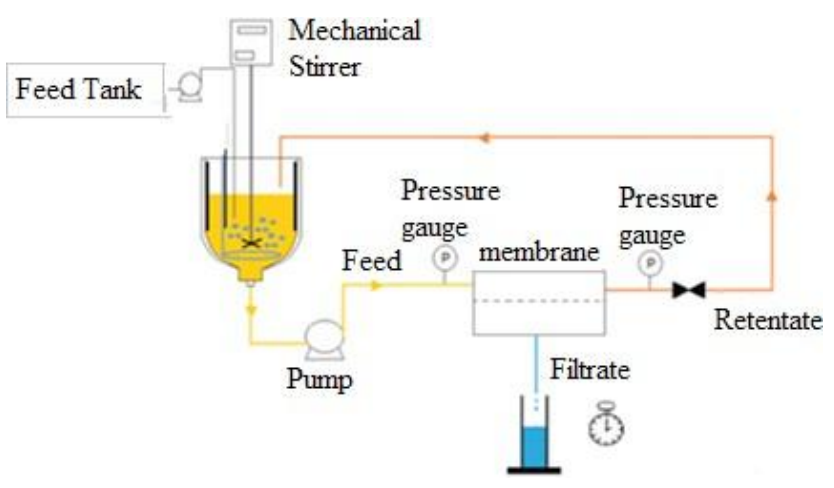

Fig. 1. Schematic representation of hybrid adsorption-UF experimental set-up.

Table 3

Pysicochemical characteristics

\begin{tabular}{|c|c|c|c|c|c|}
\hline Adsorbents & Density (g/ml) & $\begin{array}{l}\text { Molar mass } \\
(\mathrm{g} / \mathrm{mol})\end{array}$ & $\begin{array}{l}\text { Particle size } \\
(\mu \mathrm{m})\end{array}$ & $\begin{array}{l}\text { BET surface area } \\
\left(\mathrm{m}^{2} / \mathrm{g}\right)\end{array}$ & $\begin{array}{l}\text { Pore volume } \\
\left(\mathrm{cm}^{3} / \mathrm{g} \cdot \AA \AA\right)\end{array}$ \\
\hline $\mathrm{NC}$ & NR & NR & $<100$ & 80 & 0.10 \\
\hline $\mathrm{AC}$ & 0.37 & 180 & 37 & 1400 & 0.72 \\
\hline
\end{tabular}

NR : Not reported 
tion isotherm, two models commonly used to explain the dye-adsorbent interaction, the Freundlich [37] and Langmuir [38] isotherm models, were employed.

The Langmuir isotherm is based on the assumption of uniform arrangement of dye molecules and the monolayer coverage. The linearized form of Langmuir isotherm is given by Eq. (3):

$$
\frac{1}{q_{e}}=\frac{1}{q_{m}}+\frac{\square 1}{K_{L} q_{m} C_{e}}
$$

where $q_{e}(\mathrm{mg} / \mathrm{g})$ is the adsorption capacity at equilibrium state; $q_{m}(\mathrm{mg} / \mathrm{g})$ is the maximum adsorption capacity; and $K(\mathrm{~L} / \mathrm{mg})$ is the constant of Langmuir isotherm. The adsorption capacities $\left(q_{m}\right)$ and $K_{L}$ can be calculated from the linear plot of $\frac{1}{C_{e}}$ Versus $\frac{1}{q_{e}}$ [39]. The equilibrium parameter $R_{L}$ expressed in terms of a dimensionless constant separation factor indicates the type of isotherm [Eq. (4)].

$$
R_{L}=\frac{\square 1}{1+C_{i} K_{L}}
$$

where $K_{L}$ is the rate constant of Langmuir model; $C_{i}(\mathrm{mg} / \mathrm{L})$ is the initial concentration.

The separation factor $R_{L}$ value indicates whether the adsorption is favourable (o $\left.<R_{L}<1\right)$; linear $\left(R_{L}=1\right)$; unfavourable $\left(R_{L}>1\right)$.

The Freundlich isotherm model characterizes a heterogeneous system, multilayer sorption and reversible adsorption [40]. It is given by Eq. (5a):

$$
q_{e}=K_{F}\left(C_{e}\right)^{1 / n}
$$

Linearizing Eq. (5a) gives:

$$
\operatorname{Lnq} q_{e}=\operatorname{LnK}_{F}+1 / n \operatorname{LnC}_{e}
$$

where $C_{e}$ is the concentration of dye solution at adsorption equilibrium $(\mathrm{mg} / \mathrm{L}) ; q_{e}$ is the adsorption capacities $(\mathrm{mg} / \mathrm{g})$; $K_{F(\mathrm{mg} / \mathrm{g} \mathrm{L} / \mathrm{mg}))}$ are the rate constant of the Freundlich isotherm and heterogeneity index respectively.

\subsubsection{Adsorption kinetics}

Adsorption kinetic models were used to interpret the experimental data and to understand the controlling mechanism of dye adsorption and particularly to understand the characteristic of the equilibrium required for the effective sorption. Kinetics models such as pseudo-first and pseudo-second order and intra-particle diffusion that could explain the adsorption behavior [41] were employed in the investigation. Experimental data were fitted to these models and the kinetic parameters were determined. The expression of pseudo first-order is given by Eq. (6):

$\log \left(q_{e}-q_{t}\right)=\log q_{e}-\frac{k_{1} t}{2.303}$

where $q_{e}(\mathrm{mg} / \mathrm{g})$ is the amount adsorbed at equilibrium; $q_{t}$ $(\mathrm{mg} / \mathrm{g})$ is the amount adsorbed at time $\mathrm{t}$; and $k_{1}\left(\mathrm{~min}^{-1}\right)$ is the constant of pseudo first-order. For pseudo second-order kinetic model, Eq. (7) was used. $\underline{t}=\underline{1}+\underline{1} t$

$q_{t} k_{2} q^{2} q_{\mathfrak{e}}$

where $k_{2}(\mathrm{~g} / \mathrm{mg} / \mathrm{min})$ is the rate constant of pseudo sec- ondorder model. The intra-particle diffusion model is commonly used for identifying the adsorption mechanism for design purposes. The effect of intra-particle diffusion resistance on adsorption was evaluated using Eq. (8) [42]:

$q_{t}=K_{i d} t^{1 / 2}+I$

According to Eq. (8), a plot of $q$ against $t^{1 / 2}$ gives a linear graph, having which $I$ as its intercept and $K_{i d}$ as its

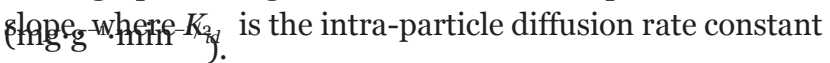

\section{Results and discussion}

\subsection{Characterisation of adsorbents}

The particle size and particle shape have been reported to be a very important property in determining the removal efficiency of natural clay (Murray 2000). The particle size distribution of $\mathrm{NC}$, determined by the laser particle size analyzer, is presented in Fig. 2. Fig. 2 indicates that the size of the NC particles is in the range of $0.1-100 \mu \mathrm{m}$, with $>60 \%$ of these particles have size $\leq 10 \mu \mathrm{m}$.

Fig. 3 shows the ATR-FTIR spectra of AC and NC stones at wave numbers in $4500-500 \mathrm{~cm}^{-1}$.

The spectrum of AC have the adsorption bands at approximately $1375.29 \mathrm{~cm}^{-1}, 1556.1 \mathrm{~cm}^{-1}$ and $3388.79 \mathrm{~cm}^{-1}$ that are assigned to the asymmetric bending vibration of the $-\mathrm{CH}_{3}$ group [43], $\mathrm{C}=\mathrm{O}$ stretching vibration of carboxylic acid or ketone [44] and to the bonded -OH group (from carboxyls, phenols or alcohols) [43], respectively. The FTIR spectrum of the NC (Fig. 3b) shows several absorption bands. The bands between 1400 and $1500 \mathrm{~cm}^{-1}$ are

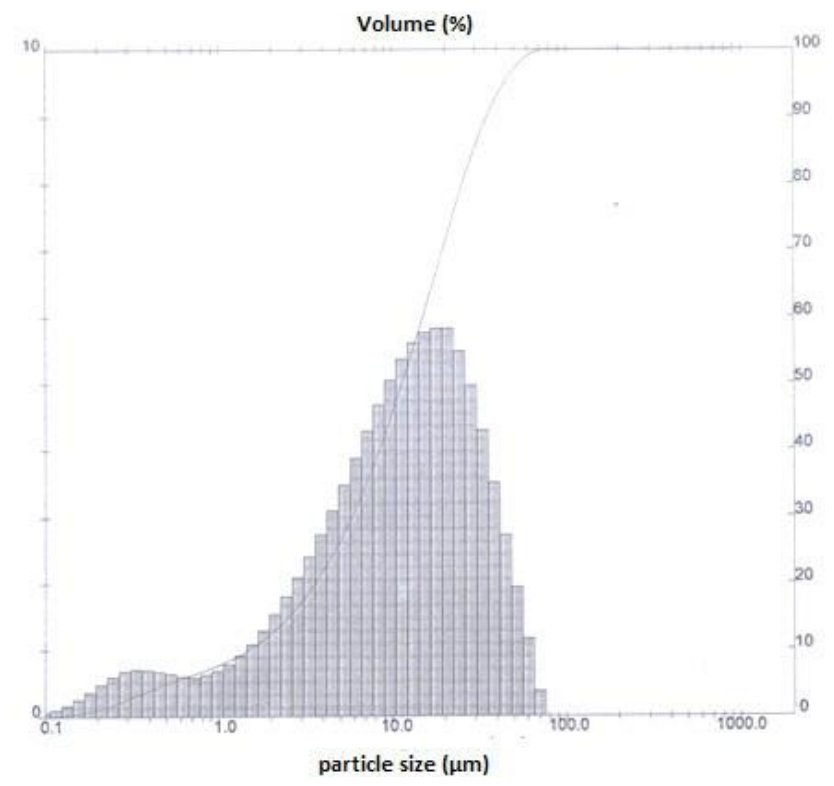

Fig. 2. Particle size distribution of NC. 

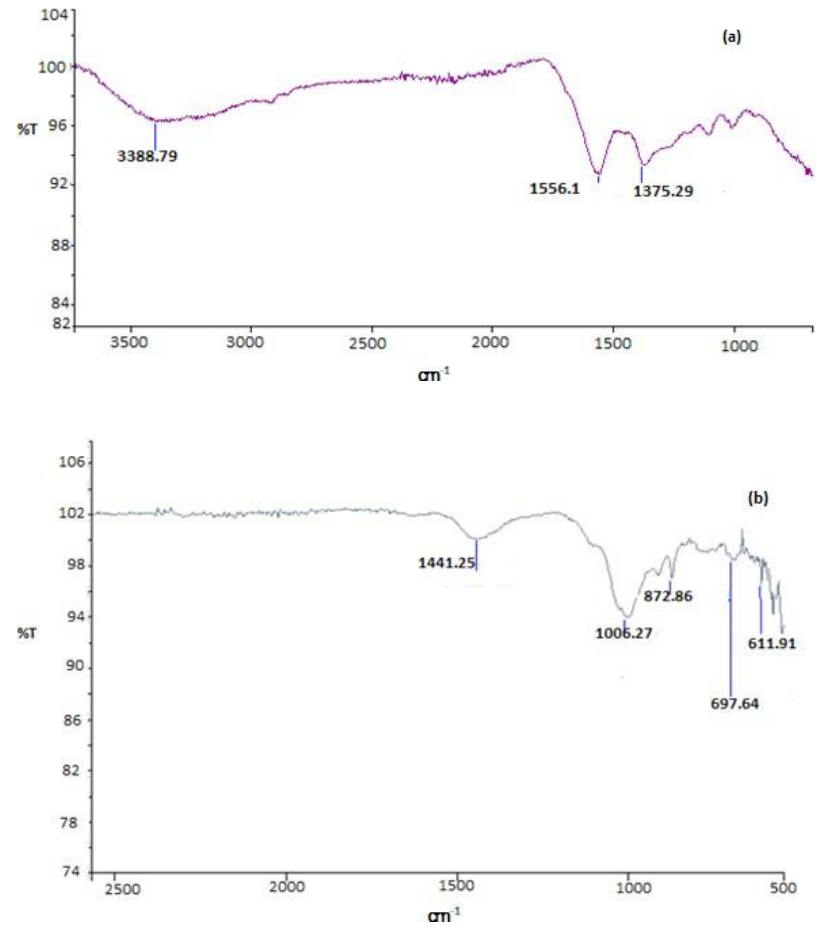

Fig. 3. FTIR spectra of AC (a) and NC (b) adsorbents.

attributed to $\mathrm{CH}_{3}$ deformation vibrations at $1441.24 \mathrm{~cm}^{-1}$ [45]. The peak located at $1006.27 \mathrm{~cm}^{-1}$ represents the valence vibrations of the $\mathrm{Si}-\mathrm{O}$ bond $[46,47]$. The absorbance band at $872.6 \mathrm{~cm}^{-1}$ corresponds to the presence of calcium carbonate $\mathrm{CaCO}_{3}$ [48]. The vibration band at $697.64 \mathrm{~cm}^{-1}$ is assigned to the deformations of $\mathrm{Si}-\mathrm{O}-\mathrm{Al}$ [45]. The peak appeared at $611.91 \mathrm{~cm}^{-1}$ is attributed to the bonded $\mathrm{Si}-\mathrm{OH}$ or $\mathrm{Si}-\mathrm{O}$ (deformation) and/or Al-O (elongation) [45].

Figs. 4a and Fig. 4b show the XRD pattern of the AC and NC, respectively. The heated activated carbon has two broad peaks in the range of $2 \theta=20^{\circ}-70^{\circ}$. The result of the $\mathrm{XRD}$ analysis for $\mathrm{AC}$ is given in Fig. 4a. As shown in Fig. $4 \mathrm{~b}$, the spectra of $\mathrm{AC}$ have two features. Both bands observed between $2 \theta=25$ and $44^{\circ}$ indicate the presence of only amorphous phase in both bands [49]. The first broad peak centered at $2 \theta=25.76^{\circ}(\mathrm{d}=3.46 \AA)$ is from the short ordered turbostratic carbon [50]. The second peak centered at $2 \theta=$ $43,58^{\circ}$ is attributed to the presence of dehydrated hemicellulose. As shown in Fig. 4b, XRD pattern of NC displays the characteristic peaks characterized by their strongest d-lines of kaolinite (7.58, 4.47 and $3.58 \AA$ ), of montmorillonite (2.54 and $1.56 \AA)$ and of quartz $(3.34,2.35,2.18,1.98,1.67 \AA)$.

\subsection{Adsorption of indigo blue dye}

The adsorption of dye from aqueous phase onto a solid surface can be well described as a reversible reaction under an equilibrium condition established between both phases [51]. The rate at which the species are removed from the solution onto an adsorbent surface is an important factor for designing treatment plants [27]. Thus, in order to understand better characterize the adsorption process, effect of operating variables such as adsorbent dose, $\mathrm{pH}$, tempera-
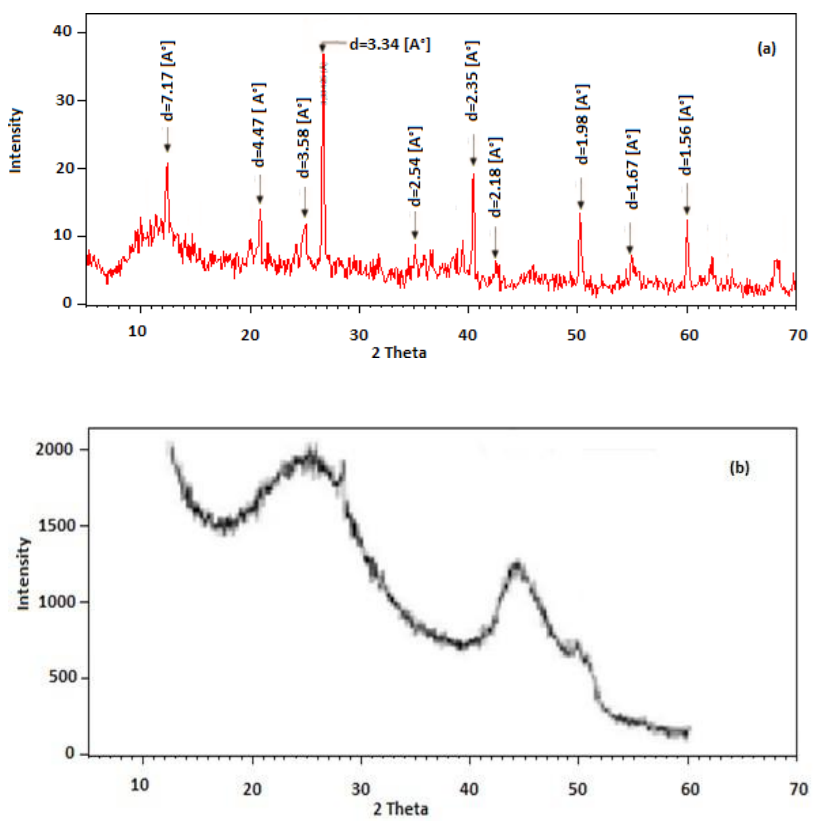

Fig. 4. X-ray diffraction of NC (a) and AC (b) adsorbents.

ture, initial dye concentration and contact time on removal of dye from the wastewater was investigated.

\subsubsection{Effect of adsorbent dosage}

Effect of the adsorbent dosage for both $\mathrm{NC}$ and $\mathrm{AC}$ on the removal of indigo dye was investigated by varying the dosage from $0.1 \mathrm{~g} / \mathrm{L}$ to $1 \mathrm{~g} / \mathrm{L}$. Experiments were carried out with $25 \mathrm{mg} / \mathrm{L}$ of dye at ambient temperature, $\mathrm{pH}$ of 11 and a contact time of 2 h. Fig. 5 shows that the percentage removal of dye increased with increasing adsorbent dosage from $0.3-0.4 \mathrm{~g} / \mathrm{L}$ and then "plateaued" afterwards. For instance, percentage removal of indigo dye increased from $0-75 \%$ when the dose of $\mathrm{AC}$ was increased from $0-0.3 \mathrm{~g} / \mathrm{L}$ and a removal percentage of $90 \%$ was obtained at $0.4 \mathrm{~g} / \mathrm{L}$ of NC. Further increase in the dosage of both adsorbents yielded no increase in percentage removal beyond these points. The observed behaviour can be attributed to the availability of more active sites on the adsorbent surface for occupations of dye molecules. The dramatic increase of color removal, from $0-75 \%$ for $\mathrm{AC}$ and from $0-90 \%$ for $\mathrm{NC}$, can be attributed to the increase of the surface area and availability of additional adsorption sites at increasing amount of adsorbent [52]. It is noteworthy to mention that the rate of dye removal increased very slow after the dose of $0.4 \mathrm{~g} / \mathrm{L}$ for $\mathrm{NC}$ and $0.3 \mathrm{~g} / \mathrm{L}$ for $\mathrm{AC}$. This could be explained by the splitting effect of flux (concentration gradient) between adsorbate and adsorbent [52]. Consequently, dose of $0.4 \mathrm{~g} / \mathrm{L}$ for $\mathrm{NC}$ and $0.3 \mathrm{~g} / \mathrm{L}$ for $\mathrm{AC}$ were taken as the optimum in this study.

\subsubsection{Effect of initial concentration}

Considering the fluctuation of the quality of the raw effluent, effect of the variation of the initial dye concentration $\left(C_{i}\right)$ was investigated within equilibrium conditions. 


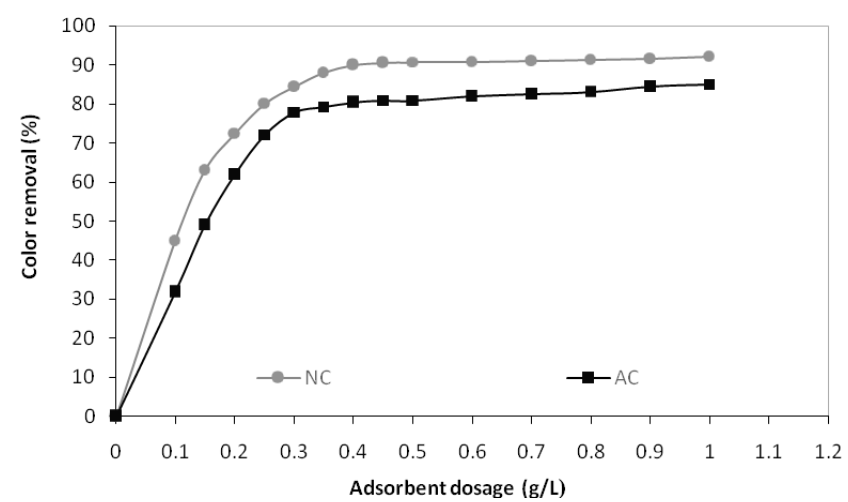

Fig. 5. Effect of adsorbent dosage of NC and AC on dye removal.

The dye solution was prepared by dissolving the indigo blue amount in $200 \mathrm{~mL}$ to make $5-40 \mathrm{mg} / \mathrm{L}$. Fig. 6 shows that the adsorption capacity $\left(q_{e}\right)$ increased from o to $48 \mathrm{mg} / \mathrm{g}$ when $C_{i}$ increased from o to $25 \mathrm{mg} / \mathrm{L}$ for $\mathrm{AC}$ and $\mathrm{o}-54 \mathrm{mg} / \mathrm{g}$ at $0-25 \mathrm{mg} / \mathrm{L}$ for NC. This increase in dye removal with an increase in amount of adsorbent is mainly due to the increased amount of the active sites. Beyond this concentration of $25 \mathrm{mg} / \mathrm{L}$, the increase of indigo blue concentration has no effect on the color removal, because the available to adsorption sites have been saturated. At high dye concentration, note that lower concentration means less adsorbate to occupy the available sites [53] or formation of dye aggregation $[54,55]$. Consequently, $25 \mathrm{mg} / \mathrm{L}$ was considered as the optimum initial dye concentration for $\mathrm{NC}$ and $\mathrm{AC}$ in the subsequent investigation.

\subsubsection{Effect of contact time}

For the determination of the optimum time at which equilibrium is reached, the contact time between the adsorbate and adsorbent was varied in the range 10-160 min. The initial concentration of indigo blue dye was kept at $25 \mathrm{mg} / \mathrm{L}$ and the dosage of NC and AC was showld be conducted to $0.4 \mathrm{~g} / \mathrm{L}$ and $0.3 \mathrm{~g} / \mathrm{L}$, respectively. Fig. 7 shows the adsorption capacity of $\mathrm{NC}$ and $\mathrm{AC}$ as a function of the contact time at ambient temperature. Similar trend could be observed regarding the behaviour of both adsorbents. The adsorption rate was significantly higher during the first $50 \mathrm{~min}$ and then slows down from 50 min until about $130 \mathrm{~min}$. Highest adsorption capacity of $52.5 \mathrm{mg} / \mathrm{g}$ and $54.5 \mathrm{mg} / \mathrm{g}$ for $\mathrm{AC}$ and NC respectively, was obtained at $140 \mathrm{~min}$. Above this value, there was almost no change in the adsorption capactity. This observations reported in previous studies where adsorption occurs rapidly within the first period of contact time and then proceeds gradually until equilibrium is reached after which the dye percentage removal remains constant [2,56-61]. Based on these results, the adopted contact time was considered as $140 \mathrm{~min}$ for both adsorbents.

The major reason for the high adsorption capacity of clay materials is their small particle size [63] that causes equilibrium to be achieved more easily, and maximum adsorption capability can be then attained. Indeed, the presence of small particles reduces internal diffusion and mass transfer limitation to the penetration of the adsorbate inside the adsorbent. Table 4 compares the performance, in terms

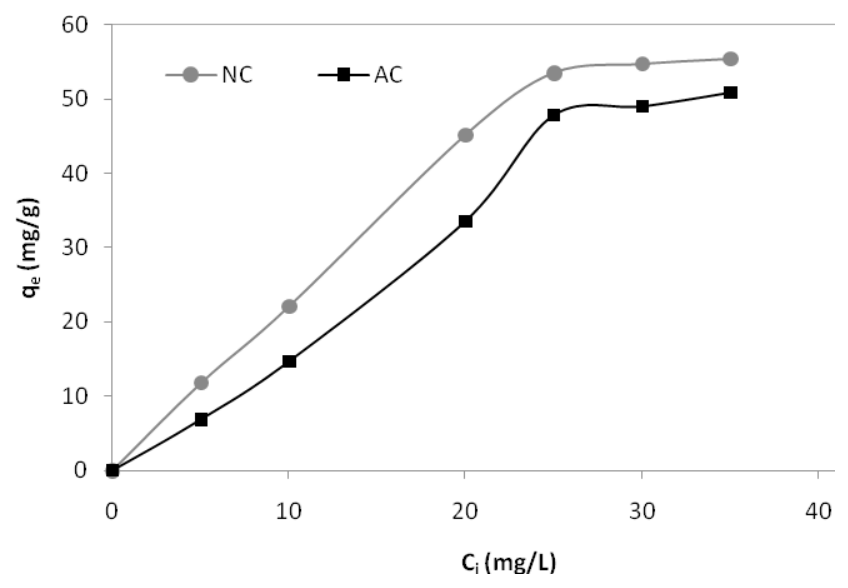

Fig. 6. Effect of initial dye concentration on adsorption of the indigo blue onto $\mathrm{NC}$ and $\mathrm{AC}$.

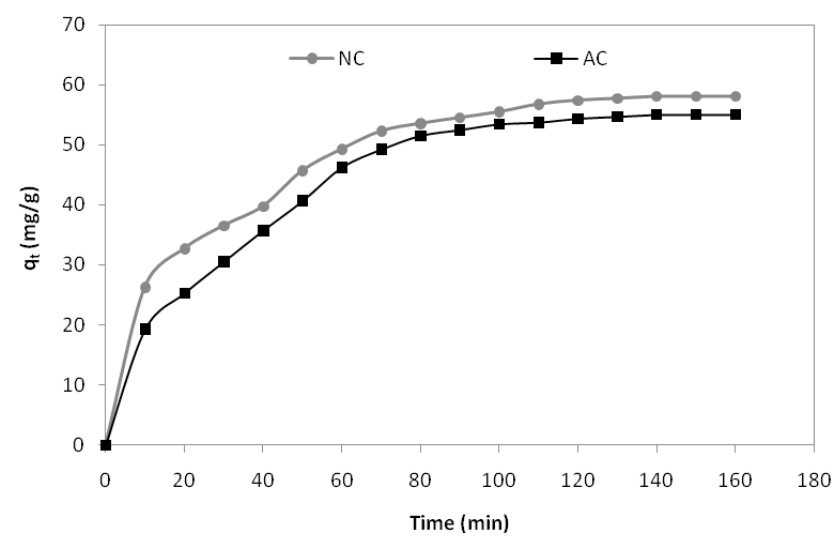

Fig. 7. Effect of the contact time on the adsorption capacity NC and $\mathrm{AC}$ for the indigo blue.

of adsorption capacity, of $\mathrm{NC}$ and $\mathrm{AC}$ for indigo blue dye obtained in this study with a few results reported in litterature. It can be seen that the natural clay (NC) shows the best performances in terms of adsorption capacity and have great potential as an effective adsorbent for indigo blue dye compared to others adsorbents.

\subsubsection{Effect of $p H$}

$\mathrm{pH}$ of adsorbate is one of the main variables affecting the adsorption process $[27,60,61,67]$. Fig. 8 presents the effect of $\mathrm{pH}(2-11)$ of indigo blue dye solution on adsorption performance; in terms of adsorption capacity, for both adsorbents (AC and NC). In general, a slight variation was obtained. Results reveal that when $\mathrm{AC}$ was used as an adsorbent, the adsorption capacity increased slightly at low $\mathrm{pH}$ from 60 $\mathrm{mg} / \mathrm{g}$ at $\mathrm{pH} 2$ to $69 \mathrm{mg} / \mathrm{g}$ at $\mathrm{pH} 7$ and then decreased to $53 \mathrm{mg} / \mathrm{g}$ at $\mathrm{pH}$ 11. With $\mathrm{NC}$, the behaviour was different because the adsorption capacity was unchanged at low $\mathrm{pH}$ until pH of 5 and then decreased slightly to $53 \mathrm{mg} / \mathrm{g}$ at $\mathrm{pH}$ 11. It is well known that the $\mathrm{pH}$ affects the surface charge of the adsorbent as well as the interaction with the dye solution [68]. 
Table 4

Surface area, particle size and adsorption capacity of different adsorbents used in the adsorption of indigo blue dye

\begin{tabular}{lllll}
\hline Adsorbents & Surface area $\left(\mathrm{m}^{2} / \mathrm{g}\right)$ & Particle size & $q_{e}(\mathrm{mg} / \mathrm{g})$ & References \\
\hline AC & 1400.00 & $37 \mu \mathrm{m}$ & 53.00 & This study \\
NC & 80.00 & $<100 \mu \mathrm{m}$ & 57.00 & This study \\
Powder activated carbon & 831.00 & $<80 \mu \mathrm{m}$ & 40.25 & {$[64]$} \\
Modified montmorillonite & $\mathrm{NR}$ & $1200 \mu \mathrm{m}$ & 9.59 & {$[65]$} \\
Modified activated carbon & $\mathrm{NR}$ & $1400 \mu \mathrm{m}$ & 9.78 & {$[65]$} \\
MCL-NP & 114.64 & $1-100 \mathrm{~nm}$ & 20.74 & {$[66]$} \\
CAC-NP & 625.61 & $1-100 \mathrm{~nm}$ & 20.40 & {$[66]$} \\
Fe/Cu nanoparticles & 162.87 & $1-100 \mathrm{~nm}$ & 20.66 & {$[66]$} \\
\hline
\end{tabular}

NR: Not reported

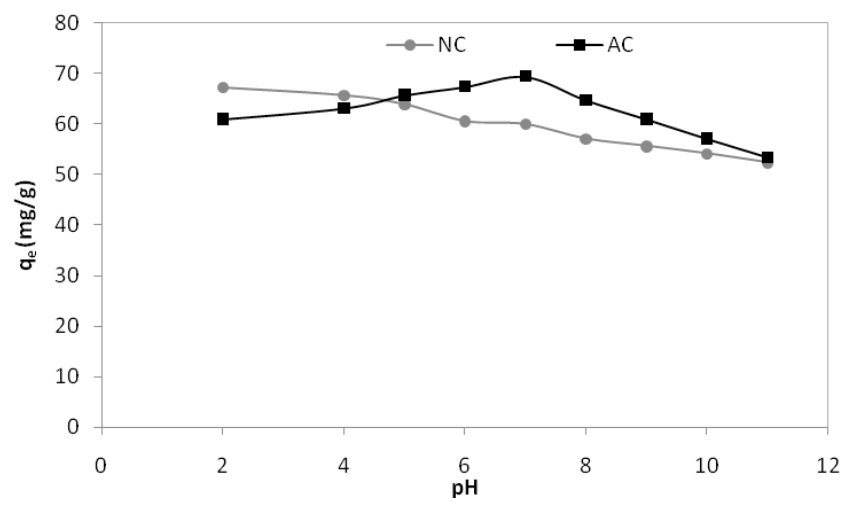

Fig. 8. Effect of $\mathrm{pH}$ on adsorption of indigo blue dye onto NC and $\mathrm{AC}$.

To explain the behaviour, the isoelectric point (IEP), i.e. the point of zero charge was determined (see Fig. 8). At a pH less than the $\mathrm{pH}$ of the IEP, the surface gets positively charged, thereby enhancing the adsorption of negatively charged indigo blue dye $(\mathrm{E}=-63 \mathrm{mV})$ onto the $\mathrm{NC}$ having an IEP of 3 . However, in the presence of AC having IEP value of 7.3, there was an increase of the adsorption capacity under the electrostatic attraction due to the uptake of anionic dye molecules by the positively charged sites until the $\mathrm{pH}$ of 7 , and then a significant decrease due to the repulsion between the negatively charged adsorbent and the negatively charged dye.

\subsubsection{Adsorption isotherms}

Analysis of adsorption isotherm is of fundamental importance to describe how adsorbate molecules interact with the adsorbent surface. Equilibrium studies determine the capacity of the adsorbent and describe the surface properties and affinity of the adsorbents. The equilibrium data for the adsorption behaviour of $\mathrm{NC}$ and $\mathrm{AC}$ at a concentration indigo blue, 25 $\mathrm{mg} / \mathrm{L}$ at an ambient temperature of $25^{\circ} \mathrm{C}$ and a contact time of $140 \mathrm{~min}$ were analyzed using two adsorption isotherm models: The Langmuir and Freundlich isotherm models. The Langmuir constants, $q_{m}$ and $K_{L}$ were determined, respectively, from the intercept and the slope of the linear plot obtained by plotting $C_{e} / q_{e}$ vs. $C_{e}$. The Freundlich isotherm constants were obtained from the plot of $\ln q_{e}$ versus $\ln C_{e}$. Isotherm constants obtained from both models are represented in Table 5 and Fig. 9. By comparing coefficient determinations $\left(\mathrm{R}^{2}\right)$, the Freundlich isotherm appears to be the best fitting model for AC and $\mathrm{NC}$ with $\mathrm{R}^{2} 99 \%$ in both cases.

It suggests that heterogeneous adsorption of indigo blue dye onto the adsorbent surface dominated [58]. This finding was also verified by the difference of results related to the capacity of adsorption between the equilibrium data for the $\mathrm{AC}$ and $\mathrm{NC}$ adsorption and the Langmuir equilibrium isotherm, as shown in Table 5 . The Freundlich exponent $1 / n$ indicates favourable condition of adsorption of indigo blue dye onto $\mathrm{NC}$ and $\mathrm{AC}$ since $1<n<10$ [69-71]. In addition, desirability of the adsorption process was also confirmed by the Langmuir separation factor $R_{L}$ since its value was between $O$ and 1 in the Langmuir model for both the adsorbents used [72].

\subsubsection{Adsorption kinetics}

The adsorption kinetics is also very useful in designing the adsorption column for the adsorption of dye, and is essential for choosing the optimum operating conditions that can influence the speed of chemical reaction and therefore interaction between the adsorbate and the adsorbent [73]. In this study, three widely-used kinetic models, including pseudo first-order, pseudo second-order and WeberMorris intra-particle diffusion, were used to find the best fitted model for the experimental data. The linear equations using the different kinetic models are shown in Fig. 10. The related values of kinetic parameters and the coefficient of determination $\left(\mathrm{R}^{2}\right)$ for adsorption of indigo blue dye solution onto $\mathrm{NC}$ and $\mathrm{AC}$ are presented in Table 6. Based on the kinetics results, poor fits of data were obtained using the intra-particle diffusion models; however, a very good fit was obtained with pseudo second-order model with a $\mathrm{R}^{2}$ of 99\% for the both adsorbents. The rate constants were more important when $\mathrm{AC}$ was used (0.023 $\mathrm{g} / \mathrm{g}$ min against 0.016 $\mathrm{g} / \mathrm{mg}$ min for $\mathrm{AC}$ ). In addition, the calculated $q_{e}$ according to pseudo second-order model is coherent with the experimental data (Table 6).

\subsubsection{Thermodynamics of adsorption}

In adsorption processes, energy must be considered in order to determine spontaneously. Thermodynamic param- 
Table 5

Adsorption isotherm parameters for the adsorption of indigo blue on $\mathrm{NC}$ and $\mathrm{AC}$

\begin{tabular}{lllllllrr}
\hline Adsorbents & \multicolumn{2}{l}{ Langmuir } & \multicolumn{3}{l}{ Freundlich } \\
\cline { 2 - 8 } & $\begin{array}{l}K_{L} \\
\left(\mathrm{dm}^{3} / \mathrm{mol}\right)\end{array}$ & $\begin{array}{l}q_{\max } \\
(\mathrm{mg} / \mathrm{g})\end{array}$ & $\mathrm{R}^{2}$ & $R_{L}$ & $\begin{array}{l}K_{F} \\
(\mathrm{mg} / \mathrm{g}(\mathrm{L} / \mathrm{mg})) 1 / \mathrm{n}\end{array}$ & $1 / n$ & $n$ & $\mathrm{R}^{2}$ \\
\hline $\mathrm{NC}$ & 6.34 & 27.17 & 0.7 & 0.71 & 48.25 & 0.49 & 2.04 & 0.99 \\
$\mathrm{AC}$ & 4.3 & 58.13 & 0.90 & 0.82 & 23.89 & 0.45 & 2.22 & 0.99 \\
\hline
\end{tabular}
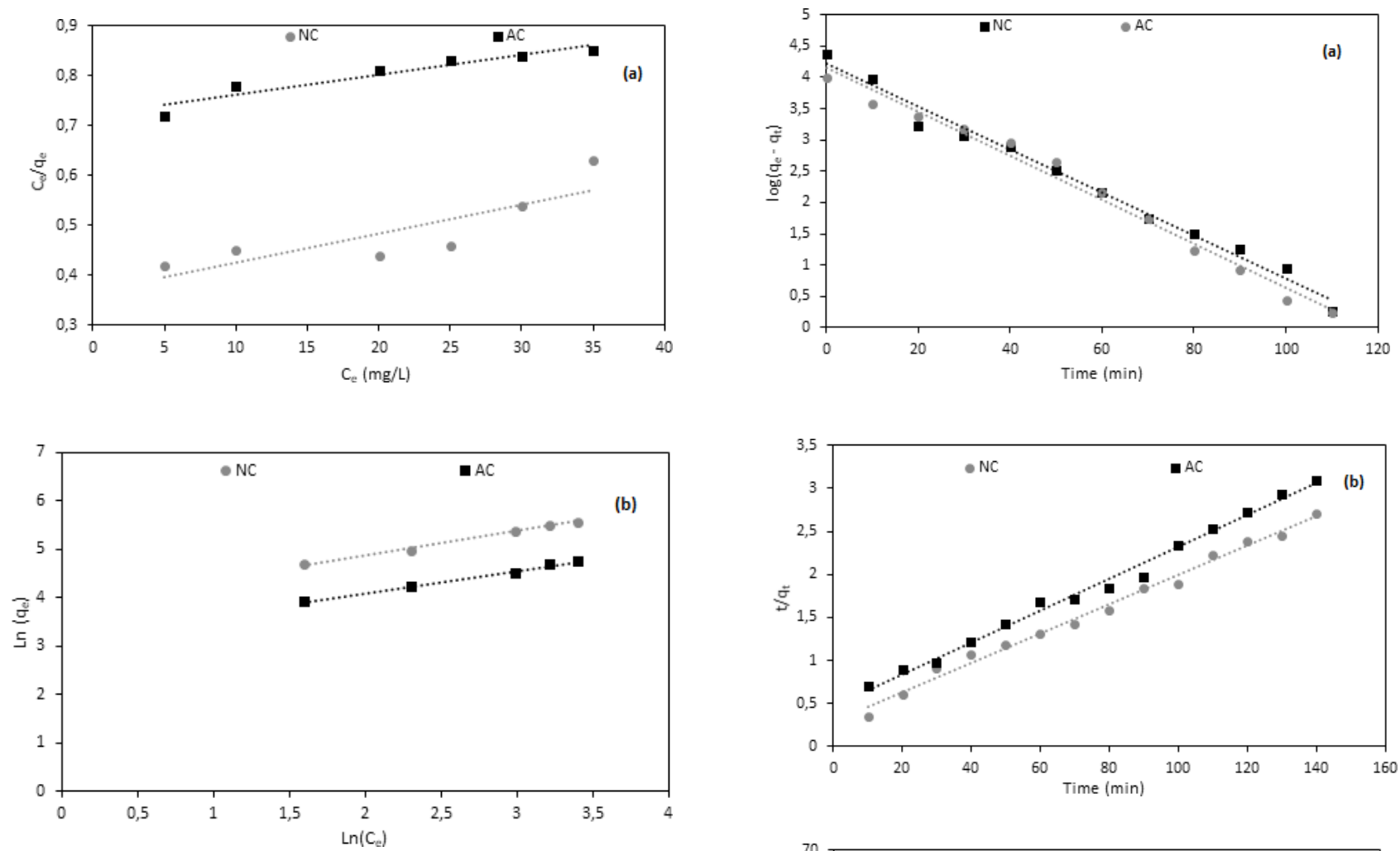

Fig. 9. Isotherm of adsorption of the indigo blue on both adsorbents: Langmuir model (a), Freundlich model (b).

eters are the indicators for practical application of a process. These parameters are obtained from the experimental data acquired at different temperatures [74] and evaluated by calculating the Gibbs free energy variation $\left(\otimes \mathrm{G}^{\circ}\right)$, enthalpy variation $\left(\otimes \mathrm{H}^{\circ}\right)$ and entropy $\left(\otimes \mathrm{S}^{\circ}\right)$ according to Eq. (8) [75,76]:

$\otimes \mathrm{G}^{\mathrm{o}}=\otimes \mathrm{H}^{\mathrm{o}}-\mathrm{T} \otimes \mathrm{S}^{\mathrm{o}}$

$\otimes \mathrm{G}^{\circ}=-R T \operatorname{Ln} K_{c}$

$\ln K_{c}=\frac{\otimes S^{\circ}}{R}-\frac{\otimes H}{R T}$

$K_{c}=\frac{q_{e}}{C_{e}}$

where $K_{c}$ the adsorption equilibrium constant; $q_{e}$ is the amount of adsorbed dye per unit mass of adsorbent $(\mathrm{mg} / \mathrm{g})$;

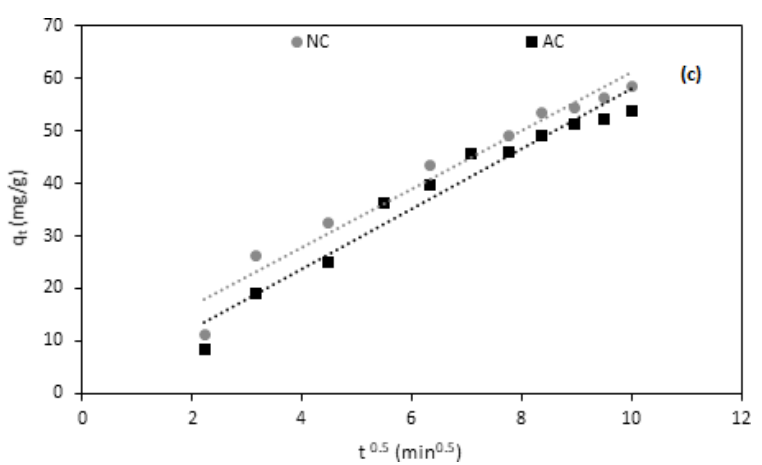

Fig. 10. Kinetics models of adsorption of the indigo blue on NC and AC: pseudo-first-order (a), pseudo-second-order (b), intra-particle diffusion (c).

$C_{e}$ is the equilibrium adsorbate concentration of dye in solution $(\mathrm{mg} / \mathrm{L}) ; \mathrm{T}$ is the temperature expressed in Kelvin $(\mathrm{K})$; and $\mathrm{R}$ is the gas constant $(\mathrm{R}=8.314 \mathrm{~J} / \mathrm{mol} \mathrm{K})$.

The plot of $\ln K_{c}$ vs. 1/T should give a linear graph, where values of $\otimes \mathrm{H}^{\circ}(\mathrm{kJ} / \mathrm{mol})$ and $\otimes \mathrm{S}^{\circ}(\mathrm{J} / \mathrm{mol} \mathrm{K})$ can $\mathbf{b}$ 
Table 6

Adsorption kinetic parameters for the adsorption of indigo blue onto NC and AC

\begin{tabular}{lllllllll}
\hline Adsorbents & \multicolumn{2}{l}{ Pseudo first order } & \multicolumn{2}{l}{ Pseudo second-order } & \multicolumn{2}{c}{ Intra-particle diffusion } \\
\cline { 2 - 9 } & $\begin{array}{l}K_{1} \\
\left(\mathrm{~min}^{-1}\right)\end{array}$ & $\begin{array}{l}q_{\text {ecal }} \\
(\mathrm{mg} / \mathrm{g})\end{array}$ & $\mathrm{R}^{2}$ & $\begin{array}{l}K_{2} \\
(\mathrm{~g} / \mathrm{mg} \mathrm{min})\end{array}$ & $\begin{array}{l}q_{\text {ecal }} \\
(\mathrm{mg} / \mathrm{g})\end{array}$ & $\mathrm{R}^{2}$ & $\begin{array}{l}K_{\text {id }} \\
\mathrm{mg} / \mathrm{g} \mathrm{min} \mathrm{min}^{-1 / 2}\end{array}$ \\
\hline $\mathrm{NC}$ & 0.078 & 67.35 & 0.98 & 0.016 & 58.47 & 0.99 & 5.55 & 0.96 \\
$\mathrm{AC}$ & 0.081 & 62.80 & 0.98 & 0.023 & 54.34 & 0.99 & 5.71 & 0.95 \\
\hline
\end{tabular}

Table 7

Thermodynamic parameters for the adsorption of indigo blue dye on $\mathrm{NC}$ and $\mathrm{AC}$ at different temperatures

\begin{tabular}{lllllll}
\hline & $\otimes \mathrm{G}^{\circ}(\mathrm{kJ} / \mathrm{mol})$ & & & & & \\
\cline { 2 - 5 } $\mathrm{T}(\mathrm{K})$ & 298 & 313 & 333 & 353 & & \\
\hline $\mathrm{AC}$ & -4.86 & -4.68 & -4.45 & -4.21 & -8.4 & -11.74 \\
$\mathrm{NC}$ & -6.73 & -6.59 & -6.4 & -6.22 & -9.46 & -9.16 \\
\hline
\end{tabular}

calculated from the slope and intercept of the Van't Hoff plots. Values of $\otimes \mathrm{G}^{\circ}(\mathrm{kJ} / \mathrm{mol})$ were calculated from $\otimes \mathrm{H}^{\circ}$ ad $\otimes S^{\circ}$. The influence of the temperature on indigo blue dye adsorption and thermodynamic behavior was investigated under the optimal condition in the range $25-80^{\circ} \mathrm{C}$ (Table 7 ). Results reveal that the adsorption capacity increased slightly with $1 / \mathrm{T}$ in the range of the $25-80^{\circ} \mathrm{C}$, attributable to the increase of the interaction between the indigo blue dye molecules and the adsorbents due to the increase of the mobility of the indigo dye molecules. The negative value of entropy $\left(\otimes S^{\circ}\right)$ indicates the spontaneous and exothermic adsorption of indigo blue dye on the adsorbent, implying that this process does not gain energy from external resources [77]. Moreover, $\otimes \mathrm{G}^{\circ}$ is less negative when the temperature increased indicating that the adsorption process is thermodynamically feasible at room temperature but less with higher temperatures. This observation suggests that the adsorption process was exothermic.

An increase of the temperature that result well as slightly decrease in the dye adsorption of NC and AC indicate an exothermic process and a favourable adsorption at lower temperature [78].

In the range of the studied temperatures from 20 to $80^{\circ} \mathrm{C}$, the standard free energyis in the range -4.86 to $-4.21 \mathrm{~kJ} / \mathrm{mol}$ for AC and -6.73 to $-6.22 \mathrm{~kJ} / \mathrm{mol}$ for $\mathrm{NC}$, suggesting that the adsorption is dominated by physisorption involving weak forces of attraction [79]. The negative value of $\otimes S^{\circ}$ for $\mathrm{NC}$ and $\mathrm{AC}$ reveals a decrease in randomness at their solid/solution interface and that no significant changes occur in the internal structure of the adsorbents through the adsorption [80].

\subsection{Performances of continuous adsorption/ultrafiltration hybrid process}

Since the size of dye molecules is smaller compared with the average pore size of UF membrane, a large proportion of molecules could pass through the membrane $[81,82]$. Therefore, the UF process coupled with adsorption is employed to achieve reasonable dye rejection/removal. The the adsorption coupling UF system, adsorption is considered as a pre-treatment step for the UF process [82].

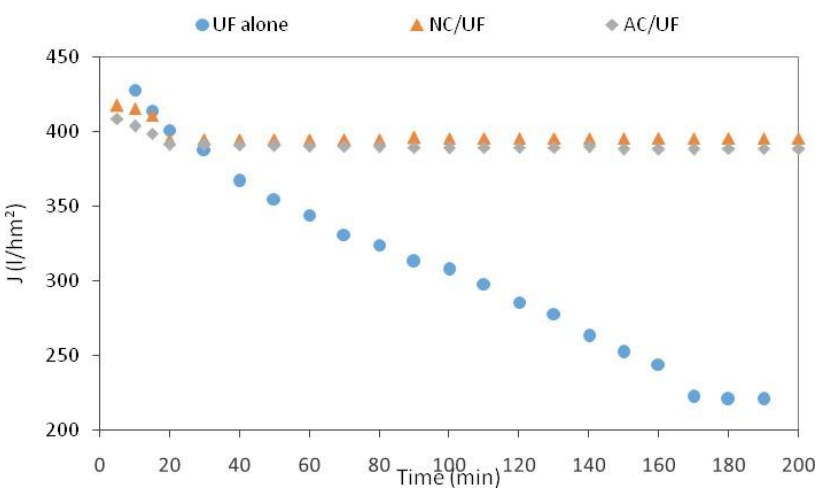

Fig. 11. Permeate flux in hybrid process $\left(\mathrm{T}=25^{\circ} \mathrm{C}, \mathrm{TMP}=3\right.$ bar $)$.

Fig. 11 shows the variation of permeate flux of synthetic indigo blue solution under both configurations, UF alone and continuous hybrid A/UF system. The dosage of $\mathrm{NC}$ and that of $\mathrm{AC}$ was $0.4 \mathrm{~g} / \mathrm{L}$ and $0.3 \mathrm{~g} / \mathrm{L}$, respectively, representing the optimal value for indigo blue aqueous solution under adsorption only. When only UF was used, the permeate flux decreases rapidly from $497 \mathrm{~L} / \mathrm{h} \mathrm{m}^{2}$ to $220 \mathrm{~L} / \mathrm{h}$ $\mathrm{m}^{2}$. This decrease of more than $50 \%$ can be related to the presence of organic and inorganic solutes in the indigo blue dye solution and the smaller size of dye molecules compared with UF membrane weight cut-off, which causes the membrane fouling by clogging the pore [83-86]. According to Fig. 11, when UF was used combined with adsorption in hybrid system, the permeate flux, at the beginning of the experiments, was lower than with UF alone and it remains almost constant during all the experiments whatever the adsorbent doses suggesting the formation of a cake layer by the adsorbent-dye species over the surface of the membrane that caused a reduction in permeate flux compared with UF alone [87]. The most amount of the dye present in the feed solution has been adsorbed by $\mathrm{NC}$ or $\mathrm{AC}$ and as a result, low quantities of indigo blue dye came in contact with the membrane. Thus, the fouling was minimum and the flux remains stable. 
The performances of the hybrid system in terms of color removal is illustrated in Fig.12.

It can be seen, the removal of the indigo blue dye increased with time to reach quasi-stabilization after 140 min for AC/UF (96.96\% ) and NC/UF (99.71\%). But using UF only, the retention rate in colour did not exceed $32 \%$. This observation confirms our previous explanation about the adsorption mechanism that prevails during the adsorption. The quasi-stabilization of the color retention is due to the saturation of AC and NC active sites [88]. Based on these results, $\mathrm{AC}$ and $\mathrm{NC}$ adsorption prior to UF greatly contributed to the high removal efficiency of the A/UF system.

\subsection{Membrane regeneration}

The application of the UF membrane is limited by the inevitable phenomena of fouling which can lower the permeate flux and might influence the retention of the pollutants and then represents a serious obstacle for the performances of membrane separation. Fouling can be reversible or irreversible. Reversible fouling can be removed easily by water rinsing or changing some process parameters, while irreversible fouling is difficult to

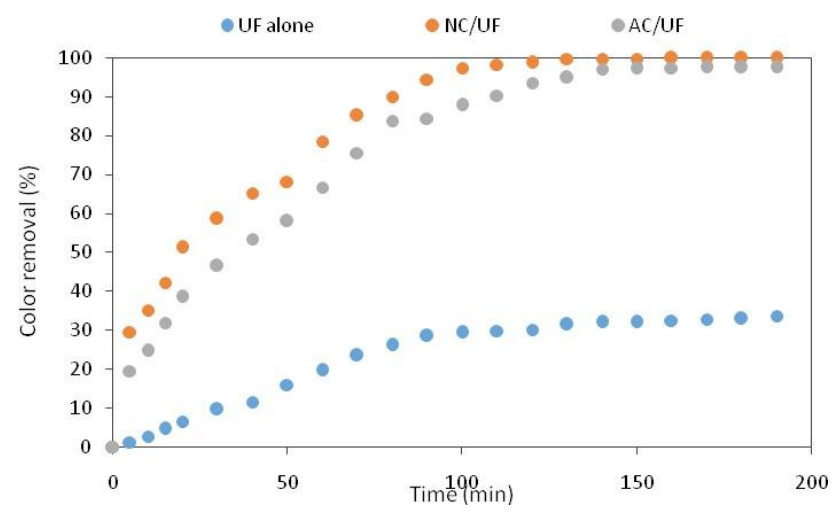

Fig. 12. Colour retention in hybrid process $\left(\mathrm{T}=25^{\circ} \mathrm{C}, \mathrm{TMP}=3\right.$ bar $)$.

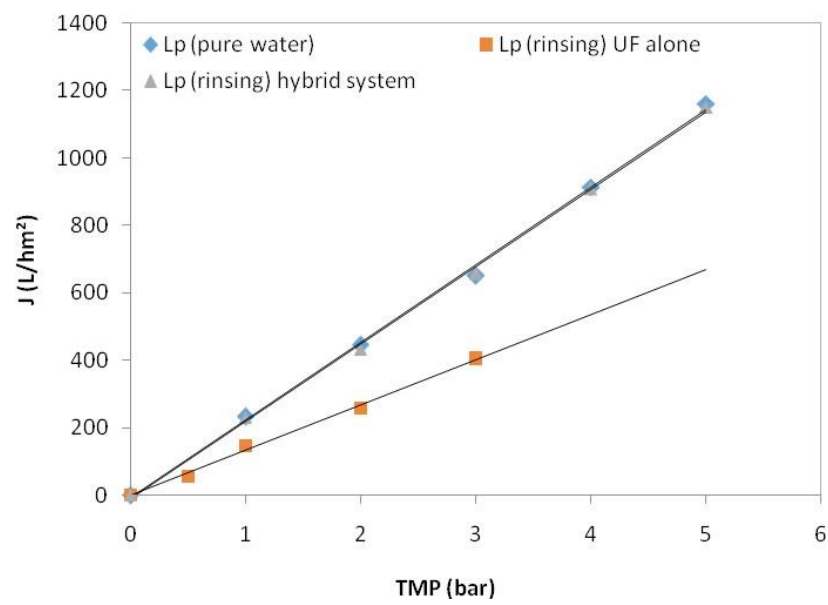

Fig. 13. Effect of transmembrane pressure on pure water and rinsing water fluxes under UF alone and hybrid adsorption/UF system. remove and might require chemical cleaning [89-91]. The efficiency of the membrane regeneration was determined by checking the water permeability. Fig. 13 represents the evolution of the permeate flux of water after rinsing the membrane with fresh water, after a simple UF and after a hybrid adsorption/UF system in presence of $\mathrm{AC}$ and NC. The results demonstrated that when the UF membrane was used alone, the water permeate flux was lower $(133 \mathrm{~L} / \mathrm{h}$ $\mathrm{m}^{2}$ bar) than that for hybrid system (230 L/h m² bar) which was quite similar to that obtained with unused membrane $\left(228 \mathrm{~L} / \mathrm{h} \mathrm{m}^{2}\right)$. These results confirm the excellent efficiency of the hybrid adsorption/UF treatment compared with the simple UF. Therefore, it can be assumed that when the fluid contains the particles of adsorbents associated to the indigo blue dye, the flow of convection towards the membrane leads to a filter cake deposit on the membrane surface having a size greater or equal to that of the pores resulting in reversible fouling, meaning that it can be eliminated in-situ with a simple water rinsing.

\section{Conclusion}

The application of adsorption and Ultrafiltration (UF) processes separately and in continuous mode for the indigo blue dye solution decolorization revealed that the best adsorption efficiency was achieved in the presence of the Tunisian Natural Clay (from Fouchana region) (NC). Therefore, the continuous adsorption/UF system shows a better separation performances in comparison to the application of UF and adsorption separately. In continuous hybrid process, the equilibrium dosage was $400 \mathrm{mg} / \mathrm{L}$ for $\mathrm{NC}$ and $300 \mathrm{mg} / \mathrm{l}$ for $\mathrm{AC}$ which represents the optimized quantity needed by a simple adsorption. A stabilized permeate flux exceeding $390 \mathrm{~L} / \mathrm{h} \mathrm{m}^{2}$ at 3 bar was then achieved in presence of AC and NC. The membrane fouling was significantly higher when UF was applied separately. Moreover, the application of the hybrid system exhibits low membrane fouling. From an environmental and economic point of view, the hybrid NC adsorption/ultrafiltration could be an efficient alternative treatment method compared to the conventional adsorption followed by UF in the case of the removal of the indigo blue dye from the textile effluent.

\section{References}

[1] H. Kono, Preparation and characterization of amphoteric cellulose hydrogels as adsorbents for the anionic dyes in aqueous solutions, Gels, 1 (2015) 94-116.

[2] M.T. Yagub, T.K. Sen, S. Afroze, H.M. Ang, Dye and its removal from aqueous solution by adsorption: a review, Adv. Colloid. Interface. Sci., 209 (2014) 172-184.

[3] N. Tholiso, R.G. Jabulani, M. Vhahangwele, M. Arjun, An update on synthetic dyes adsorption onto clay based minerals: A state-of-art review, J. Environ. Manag., 191 (2017) 35-57.

[4] N. Ertugay, F.N. Acer, Removal of COD and color from direct blue 71 azo dye wastewater by fenton's oxidation: Kinetic study, Arab. J. Chem., 10 (2017) S1158-S1163.

[5] M.A. Hassaan, A. El Nemr, F.F. Madkour, Advanced oxidation processes of mordant violet 40 dye in freshwater and seawater, Egypt. J. Aquat. Res., 43 (2017) 1-9.

[6] M.A. Hassaan, A. El Nemr, F.F. Madkour, Testing the advanced oxidation processes on the degradation of direct blue 86 dye in wastewater, Egypt. J. Aquat. Res., 43 (2017) 11-19. 
[7] C.J. Escudero, O. Iglesias, S. Dominguez, M.J. Rivero, I. Ortiz, Performance of electrochemical oxidation and photocatalysis in terms of kinetics and energy consumption. New insights into the p- cresol degradation, J. Environ. Manage., 195(2017) 117-124.

[8] E.E. Ebrahiem, M.N. Al-Maghrabi, A.R. Mobarki, Removal of organic pollutants from industrial wastewater by applying photo-fenton oxidation technology, Arab. J. Chem., 10 (2017) S1674-S1679.

[9] D. Karisma, G. Febrianto, D. Mangindaan, Removal of dye from textile wastewater by using nanofiltration polyetherimide membrane, Environ. Earth. Sci., 109 (2017) 1-7.

[10] V. Buscio, M.J. Marín, M. Crespi, C. Gutiérrez-Bouzán, Reuse of textile wastewater after homogenization-decantation treatment coupled to PVDF ultrafiltration membranes, Chem. Eng. J., 265 (2015) 122-128.

[11] D. Bhatia, N.R. Sharma, J. Singh, R.S. Kanwar, Biological methods for textile dye removal from wastewater: A review, Crit. Rev. Env. Sci. Tec., 47 (2017) 1836-1876.

[12] B. Abbasi, Removal of dye by biological using fungi, Int. J. Med. Rev., 4 (2017) 112-118.

[13] B. Gezer, Adsorption capacity for the removal of organic dye pollutants from wastewater using carbon powder, Int. J. Agric. For., 2 (2018) 1-14.

[14] M. EL Alouani, S. Alehyen, M. EL Achouri, M. Taibi, Removal of cationic dye-methylene blue from aqueous solution by adsorption on fly ash-based geopolymer, J. Mater. Environ. Sci., 9 (2018) 32-46.

[15] C. Manera, A.P. Tonello, D. Perondi, M. Godinho, Adsorption of leather dyes on activated carbon from leather shaving wastes: Kinetics, equilibrium and thermodynamics studies, Environ. Technol., (2018) 1-13.

[16] M. Turabik, Adsorption of basic dyes from single and binary component systems onto bentonite: simultaneous analysis of Basic Red 46 and Basic Yellow 28 by first order derivative spectrophotometricanalysismethod,J.Hazard.Mater.,158(2008)52-64.

[17] C.C. Wang, L.C. Juang., T.C. Hsu, C.K. Lee, J.F. Lee, F.-C. Huang, Adsorption of basic dyes onto montmorillonite, J. Colloid. Interface. Sci., 273 (2004) 80-86.

[18] D. Pathania, D. Gupta, H. Al-Muhtaseb, G. Sharma, A. Kumar, M. Naushad, T. Ahmed, S.M. Alshehri, Photocatalytic degradation of highly toxic dyes using chitosan-g-poly(acrylamide)/ $\mathrm{ZnS}$ in presence of solar irradiation, J. Photochem. Photobiol. A. Chem., 329 (2016) 61-68.

[19] L. Gnanasekaran, R. Hemamalini, M. Naushad, Efficient photocatalytic degradation of toxic dyes using nanostructured $\mathrm{TiO}_{2} /$ polyaniline nanocomposite, Desal. Water Treat., 108 (2018) 322-328.

[20] D. Yanan, S. Yanlei, C. Wenjuan, P. Jinming, Z. Yan, J. Zhongyi, Ultrafiltration enhanced with activated carbon adsorption for efficient dye removal from aqueous solution, Chinese J. Chem. Eng., 19 (2011) 863-869.

[21] L.C. Schideman, B.J. Marinas, V.L. Snoeyink, S.Y. Qi, C. Campos, Three-component adsorption modeling to evaluate and improve integrated sorption-membrane processes, Environ. Sci. Technol., 41 (2007) 6547-6553.

[22] A.Y. Zahrim, C. Tizaoui, N. Hilal, Coagulation with polymers for nanofiltration pre-treatment of highly concentrated dyes: A review, Desalination, 266 (2011) 1-16.

[23] Y. Matsui, F. Colas, A. Yuasa, Removal of a synthetic organic chemical by PAC-UF systems. II: Model application, Water Res., 35 (2001) 464-470.

[24] V. Vipasiri, L. Shaomin, J. Bo, W.K. Chris Chowd, S. Chris, Kinetic study and equilibrium isotherm analysis of Congo Red adsorption by clay materials, Chem. Eng. J., 148 (2009) 354-364.

[25] S. Sangon, A.J. Hunt, T.M. Attard, P.Mengchang, Y. Ngernyen, N. Supanchaiyamat, Valorisation of waste rice straw for the production of highly effective carbon based adsorbents for dyes removal, J. Clean. Prod., 172 (2018) 1128-1139.

[26] T.L. Silva, A.L. Cazetta, P.S.C. Souza, T. Zhang, T. Asefa, V.C. Almeida, Mesoporous activated carbon fibers synthesized from denim fabric waste: effcient adsorbents for removal of textile dye from aqueous solutions, J. Clean. Prod., 171 (2018) 482-490.
[27] E. Errais, J. Duplay, F. Darragi, I. M’Rabet, A. Aubert, F. Huber, G. Morvan, Efficient anionic dye adsorption on natural clay: Kinetic study and thermodhynamic parameters, Desalination, 275 (2011) 74-81.

[28] G. Bayramoglu, B. Altintas, M.Y. Arica, Adsorption kinetics and thermodynamic parameters of cationic dyes from aqueous solutions by using a new strong cationexchange resin, Chem. Eng. J., 152 (2009) 339-346.

[29] Y. Hu, T. Guo, X. Ye, Q. Li, M. Guo, H. Liu, Z. Wu, Dye adsorption by resins: effect of ionic strength on hydrophobic and electrostatic interactions, Chem. Eng. J., 228 (2013) 392-397.

[30] M. Naushad, Z.A. ALOthman, M.R. Awual, S.M. Alfadul, T. Ahamad, Adsorption of rose Bengal dye from aqueous solution by amberlite Ira-938 resin: kinetics, isotherms, and thermodynamic studies, Desal. Water Treat., 57(29) (2016) 13527-13533.

[31] P. Senthil Kumar, R. Sivaranjanee, U. Vinothini, M. Raghavi, K. Rajasekar, K. Ramakrishnan, Adsorption of dye onto raw and surface modified tamarind seeds: isotherms, process design, kinetics and mechanism, Desal. Water Treat., 52(13-15) (2014) 2620-2633.

[32] E. Daneshvar, A. Vazirzadeh, A. Niazi, M. Kousha, M. Naushad, A. Bhatnagar, Desorption of methylene blue dye from brown macroalga: effects of operating parameters, isotherm study and kinetic modeling, J. Clean. Prod., 152 (2017) 443453 .

[33] W.T. Tsai, C.Y. Chang, C.H. Ing, C.F. Chang, Adsorption of acid dyes from aqueous solution on activated bleaching earth, J. Colloid Interf. Sci., 275 (2004) 72-78.

[34] S.C.R. Santos, A.F.M. Oliveira, R.A.R. Boaventura, Bentonitic clay as adsorbent for the decolourisation of dyehouse effluents, J. Clean. Prod., 126 (2016) 667-676.

[35] K. Zhou, Q. Zhang, B. Wang, J. Liu, P. Wen, Z. Gui, Y. Hu, The integrated utilization of typical clays in removal of organic dyes and polymer nanocomposites, J. Clean. Prod., 81 (2014) 281-289.

[36] N. Abidi, E. Errais, J. Duplay, A. Berez, A. Jrad, G. Schafer, M. Ghazi, K. Semhi, M. Trabelsi-Ayadi, Treatment of dye-containing effluent by natural clay, J. Clean. Prod., 86 (2015) 432-440.

[37] H.M.F. Freundlich, Über die adsorption in lösungen, Z. Phys. Chem., 57 (1906) 385-470.

[38] S. Elemen, E.P.A. Kumbasar, S. Yapar, Modeling the adsorption of textile dye on organoclay using an artificial neural network Dyes Pigments, 95 (2012) 102-111.

[39] K. El Ass, Adsorption of cadmium and copper onto natural clay: isotherm, kinetic and thermodynamic studies, Global NEST J., 20 (2018) 1-10.

[40] M. Kermania, H. Izanloo, R.R. Kalantary, H.S. Barzaki, B. Kakavandi, Study of the performances of low-cost adsorbents extracted from Rosa damascena in aqueous solutions decolorization, Desal. Water Treat., 80 (2017) 357-369.

[41] K. Allam, K. Gourai, A. EL Bouari, B. Belhorma, L. Bih, Adsorption of Methylene Blue on raw and activated clay: case study of Bengurir clay, J. Mater. Environ. Sci., 9 (2018) 1750-1761.

[42] H. Aghdasinia, H.R. Asiabi, Adsorption of a cationic dye (methylene blue) by Iranian natural clays from aqueous solutions: equilibrium, kinetic and thermodynamic study, Environ. Earth. Sci., 77 (2018) 218-231.

[43] M.B. Benzekri, N. Benderdouche, B. Bestani, N. Douara, L. Duclaux, Valorization of olive stones into a granular activated carbon for the removal of Methylene blue in batch and fixed bed modes, J. Mater. Environ. Sci., 9 (2018) 272-284.

[44] J. Starck, P. Burg, S. Muller, J. Bimer, G. Furdin, P. Fioux, C. Vix-Guterl, D. Begin, P. Faure, B. Azambre, The influence of demineralisation and ammoxidation on the adsorption properties of an activated carbon prepared from a Polish lignite, Carbon, 44 (2006) 2549-2557.

[45] A. Loqman, B. El Bali, J. Lützenkirchen, P.G. Weidler, A. Kherbeche, Adsorptive removal of crystal violet dye by a local clay and process optimization by response surface methodology, Appl. Water Sci., 7 (2017) 3649-3660.

[46] N. Shehata, M.S. El-Geundi, E.A. Ashour, R.M.A. Abobeah, Structural characteristics of the egyptian clay as a low cost adsorbent, J. Chem. Eng. Res., 3 (2016) 35-45. 
[47] O. Qabaqous, N. Tijani, M. Naciri Bennani, A. El Krouk, Preparation and characterization of supports plans from the (Rhassoul) clay for mineral membranes, Mater. Environ. Sci., 5 (2014) 2244-2249.

[48] A. Qlihaa, S. Dhimni, F. Melrhaka, N. Hajjaji, A. Srhiri, Physico-chemical characterization of a morrocan clay, J. Mater. Environ. Sci., 7 (2016) 1741-1750.

[49] M.N. Sepehr, M. Zarrabi, H. Kazemian, A. Amrane, K. Yaghmaian, H.R. Ghaffari, Removal of hardness agents, calcium and magnesium, by natural and alkaline modified pumice stones in single and binary systems, Appl. Surf. Sci., 274 (2013) 295-305.

[50] S.W. Won, H.J. Kim, S.H. Choi, B.W. Chung, K.J. Kim, Y.S Yun, Performance kinetics and equilibrium in biosorption of anionic dye reactive black 5 by the waste biomass of Corynebacterium glutamicum as a low-cost biosorbent, Chem. Eng. J., 21 (2006) 37-43

[51] A.R. Tehrani-Bagha, H. Nikkar, N.M. Mahmoodi, M. Markazi, F.M. Menger, The sorption of cationic dyes onto kaolin: Kinetic, isotherm and thermodynamic studies, Desalination, 266 (2011) 274-280.

[52] Y. Zhou, L. Ge, N. Fan, M. Xia, Adsorption of Congo red from aqueous solution onto shrimp shell powder, Adsorpt. Sci. Technol., (2018) 1-21.

[53] F. Ayari, S. Khelifi, M. Trabelsi-Ayadi, Synthesized and characterization of organobentonite for anionic dye removal: Application to real textile effluent, Environ. Technol., (2018) 1-32.

[54] I. Chaari, B. Moussi, F. Jamoussi, Interactions of the dye, C.I. direct orange 34 with natural clay, J. Alloys Compd., 647 (2015) $720-727$.

[55] O.T. Ogunmodede, A.A. Ojo, E. Adewole, O.L. Adebayo, Adsorptive removal of anionic dye from aqueous solutions by mixture of Kaolin and Bentonite clay: characteristics, isotherm, kinetic and thermodynamic studies, Iran. J. Energy Environ., 6 (2015) 147-153.

[56] M. Naushad, T. Ahamad, B.M. AL-Maswari, A.A. Alqadami, S.M. Alshehri, Nickel ferrite bearing nitrogen-doped mesoporous carbon as efficient adsorbent for the removal of highly toxic metal ion from aqueous medium, Chem. Eng. J., 330 (2017) 1351-1360

[57] K.O. Adebowale, B.I. Olu-Owolabi1, E.C. Chigbundu, Removal of Safranin-O from aqueous solution by adsorption onto Kaolinite clay, J. Encap. Adsorp. Sci., 4(2014) 89-104.

[58] K. Chinoune, K. Bentale, Z. Bouberka, A. Nadim, U. Maschke, Adsorption of reactive dyes from aqueous solution by dirty bentonite, Appl. Clay Sci., 123 (2016) 64-75.

[59] R. Elmoubarki, F.Z. Mahjoubi, H. Tounsadi, J. Moustadraf, M. Abdennouri, A. Zouhri, A. ElAlban, N. Barka, Adsorption of textile dyes on raw and decanted Moroccan clays: kinetics, equilibrium and thermodynamics, Water Resour. Industry, 9 (2015) 16-29.

[60] M. Fayazi, D. Afzali, M.A. Taher, A. Mostafavi, V.K. Gupta, Removal of Safranin dye from aqueous solution using magnetic mesoporous clay: optimization study, J. Mol. Liq., 212 (2015) 675-685

[61] Y. Kismir, A.Z. Aroguz, Adsorption characteristics of the hazardous dye brilliant green on saklikent mud, Chem. Eng. J., 172 (2011) 199-206.

[62] G.R. Mahdavinia, A. Baghban, S. Zorofi, A. Massoudi, Kap- paCarrageenan biopolymer-based nanocomposite hydrogel and adsorption of methylene blue cationic dye from water, J. Mater. Environ. Sci., 5 (2014) 330-337.

[63] T. Lakdioui, A. El Harfi, Elimination of indigo dyes existing in liquid discharges by ultrafiltration processes and adsorption, Mor. J. Chem., 3 (2015) 441-448.

[64] P.T. Almazán-Sánchez, M.J. Solache-Ríos, I. Linares Hernández, V. Martínez-Miranda, Adsorption-regeneration by heterogeneous Fenton process using modified carbon and clay materials for removal of indigo blue, Environ. Technol., 37 (2016) $1843^{-1856 .}$

[65] X. Zhu, L. Bao, Y. Wei, J. Ma, Y. Kong, Removal of toxic indigo blue with integrated biomaterials of sodium carboxymethyl cellulose and chitosan, Int. J. Biol. Macromol., 91 (2016) 409415 .
[66] E. Errais, J. Duplay, M. Elhabiri, M. Khodja, R. Ocampo, R. Baltenweck-Guyot, F. Darragi, Anionic RR120 dye adsorption onto raw clay: Surface properties and adsorption mechanism, Colloids Surf., 403 (2012) 69-78.

[67] A. Hammami, C. Charcosset, R. Ben Amar, Performances of conventional activated carbon and low-cost adsorbent from clay and mineral coal in decolorization of $\mathrm{AO} 7$ solution, Desal. Water Treat., 146 (2019) 188-196.

[68] A. Gurusamy, J. Ruey-Shin, L. Duu-Jong, Use of cellulose based wastes for adsorption of dyes from aqueous solutions, J. Hazard. Mater., B92 (2002) 263-274.

[69] B.H. Hameed, D.K. Mahmoud, A.L. Ahmad, Equilibrium modeling and kinetic studies on the adsorption of basicdye by a low-cost adsorbent: Coconut (Cocos nucifera) bunch waste, J. Hazard. Mater., 158 (2008) 65-72.

[70] L.T. Nanganoa, J.M. Ketcha, J.N. Ndi, Kinetic and equilibrium modeling of the adsorption of amaranth from aqueous solution onto smectite clay, Res. J. Chem. Sci., 4 (2014) 7-14.

[71] R. Rezaei Kalantry, A. Jonidi Jafari, A. Esrafili, B. Kakavandi, A. Gholizadeh, A. Azari, Optimization and evaluation of reactive dye adsorption on magnetic composite of activated carbon and iron oxide, Desal. Water Treat., 57(14) (2016) 6411-6422.

[72] A. Kausar, M. Iqbal, A. Javed, K. Aftab, Z.H. Nazli, H.N. Bhatti, S. Nouren, dyes adsorption using clay and modified clay: A review, J. Mol. Liq., 256 (2018) 395-407.

[73] R. Fabryanty, C. Valencia, F.E. Soetaredjo, J.N. Putro, S.P. Santoso, A. Kurniawan, S. Ismadji, Removal of crystal violet dye by adsorption using bentonite-alginate composite, J. Environ. Chem. Eng, 5 (2017) 5677-5687.

[74] O. Sözüdoğru, B.A. Fil, R. Boncukcuoğlu, E. Aladağ, , S. Kul, Adsorptive removal of cationic (BY2) dye from aqueous solutions onto Turkish clay: Isotherm, kinetic, and thermodynamic analysis, Particul. Sci. Technol., 34 (2015) 103-111.

[75] A.K. Kushwaha, G. Neha, M.C. Chattopadhyaya, Removal of cationic methylene blue and malachite green dyes from aqueous solution by waste materials of Daucus carota, J. Saudi Chem. Soc., 18 (2014) 200-207.

[76] B. Kakavandi, A. Jonidi Jafari, R. Rezaei Kalantary, S. Nasseri, A. Ameri, A. Esrafily, Synthesis and properties of $\mathrm{Fe}_{3} \mathrm{O}_{-}^{-}$activated carbon magnetic nanoparticles for removal of aniline from aqueous solution: equilibrium, kinetic and thermodynamic studies, Iran. J. Environ. Health Sci. Eng., 10 (2013) 1-9.

[77] B. Meroufel, O. Benyahia, Y. Benmoussa, M.A. Zenasni, Adsorptive of anionic dye from aqueous solutions by Algerian kaolin: characteristics, isotherm, kinetic and thermodynamic studies, J. Mater. Environ. Sci., 4 (2013) 482-491.

[78] B.S. Chu, B.S. Baharin, Y.B.C. Quek, Separation of vitamin E from palm fatty acid distillate using silica: Equilibrium of batch adsorption, J. Food Eng., 62 (2004) 97-103.

[79] M.K. Purkait, A. Maiti, S. Dasgupta, S. De, Removal of congo red using activated carbon and its regeneration, J. Hazard. Mater., 145 (2007) 287-295.

[80] H. Susanto, M. Ulbricht, Influence of ultrafiltration membrane characteristics on adsorptive fouling with dextrans, J. Membr. Sci., 266 (2005) 132-142.

[81] M. Campinas, M.J. Rosa, Removal of microcystins by PAC/UF, Sep. Purif. Technol., 71 (2010) 114-120.

[82] B. Van der Bruggen, L. Braeken, C. Vandecasteele, Flux decline in nanofiltration due to adsorption of organic compounds, Sep. Purif. Technol., 29 (2002) 23-31.

[83] Z. He, D.J. Miller, S. Kasemset, L. Wang, D.R. Paul, B.D. Freeman, Fouling propensity of a poly(vinylidene fluoride) microfiltration membrane to several model oil/water emulsions, J. Membr. Sci., 514 (2016) 659-670.

[84] L. Jieun, V. Saravanamuth, Z. Yongshun, S.P.R.R. Ramireddy, L. Zongwen, Effective natural organic matter removal in pond water by carbon nanotube membrane with flocculation/adsorption, Water Sci. Technol: Water Supply, 17(4) (2017) 1080-1087.

[85] L. Mathilde, M. Alice, C. Julien, P. Yves, B. Laurent, D. Alain, Effect of high-hydrostatic-pressure-treated skim milk on permeate flux and fouling during ultrafiltration, J. Dairy Sci., 100 (2017) 1-12. 
[86] Z. He, D.J. Miller, S. Kasemset, L. Wang, D.R. Paul, B.D. Freeman, Fouling propensity of a poly(vinylidene fluoride) microfiltration membrane to several model oil/water emulsions, J. Membr. Sci., 514 (2016) 659-670.

[87] C. Tansakul, S.C. Laborie, Cabassud, Adsorption combined with ultrafiltration to remove organic matter from seawater, Water Res., 45 (2011) 6362-6370.

[88] N. Dhakal, S.G. Salinas-Rodriguez, A. Ouda, J.C. Schippers, M.D. Kennedy, Fouling of ultrafiltration membranes by organic matter generated by marine algal species, J. Membr. Sci., 555 (2018) 418-428.
[89] H. Chang, B. Liu, H. Liang, H. Yu, S. Shao, G. Li, Effect of filtration mode and backwash water on hydraulically irreversible fouling of ultrafiltration membrane, Chemosphere, 179 (2017) 254-264.

[90] T. Nouha, J. Ilyes, A. Salwa, C. Sophie, C. Marc, B.A. Raja, Preparation of an asymmetric microporous carbon membrane for ultrafiltration separation: application to the treatment of industrial dyeing effluent, Desal. Water Treat., 57(50) (2016) 23473-23488. 